\title{
Walter L. Brown Appointed Editor of Journal of Materials Research
}

Walter $\mathrm{L}$. Brown has been appointed Editor-in-Chief of Journal of Materials $R_{p}$ search effective Ja nuary 1,1987 . JMR, which has completed its inaugural year, is the official journal of the Materials Research Society, and is the first international forum to encompass physical, chemical, and engineering insights on advanced materials and processing techniques.

"Brown served as a Principal Editor for Journal of Materials Research during 1986, contributing greatly to its success. We are pleased that his broad knowledge and contributions to the field of materials research will now serve as the guiding force behind JMR," stated MRS President Gordon E. Pike.

Brown received a $B S$ in physics from Duke University in 1945. He attended graduate school at Harvard, where he received his MA in 1947, and PhD in 1951. Brown joined the research department of AT\&T Bell Laboratories in November of 1950 and has been head of the Radiation Physics Research Department since 1958.

Brown's early experiments at Bell Labs with Brattain, Shockley, and Fletcher laid the foundation of understanding of surface states and inversion layers of silicon and germanium that made possible the development of MOSFET technology. His interest in semiconductors led to the design of solid state radiation detectors that were flown in the first Telstar experimental communications satellite, and which were used to determine the nature of the particles that are trapped in the Van Allen belts. The success of this set of experiments led to the formulation of magnetospheric research programs at Bell Labs, and netted significant advances in the understanding of semiconductor materials, particularly the boron and phosphorus diffusion processes that are so fundamental to today's semiconductor industry.

In the early 1960s, Brown's interest in particle detectors and high-energy particle damage led to his involvement, together with J.A. Burton, in the organization of a joint program with Rutgers University that would serve to provide shared equipment and eventually to stimulate the interest and dedicated efforts of a large number of materials scientists. The Rutgers UniversityBell Laboratories Accelerator Laboratory and Walter Brown's research department at Bell Labs were at the center of a global interest in the phenomenon of particle channeling and blocking in crystals. Using channeling techniques to diagnose the effects of implantation, Brown and colleagues successfully generated techniques



\section{W.L. Brown}

for the successful use of implantation in producing semiconductor devices.

Most recently, Walter Brown has directed his research to laser-solid interactions. Brown and his colleagues were first to demonstrate that the annealing of implantation damage by cw laser irradiation is accomplished in the solid phase; i.e., does not involve melting.

Walter Brown is a member of the Materials Research Society, where he presently serves as Councillor. He chaired the 1984 MRS Fall Meeting and has served on numerous committees. He received the Society's highest honor, the Von Hippel Award, in 1984. He is also a member of the American Association for the Advancement of Science, a Fellow of the American Physical Society, and was recently elected to both the National Academy of Sciences and National Academy of Engineering.

"Walter Brown's creativity and vision epitomizes the philosophy of Journal of Materials Research," Pike said. "Under his direction, JMR will continue to bring leading edge materials research to the research community."

Journal of Materials Researih is published six times a year for MRS by the American Institute of Physics. Editorial submissions and inquiries should be sent to Editorial Office, Journal of Materials Research, Materials Research Society, 9800 McKnight Road, Suite 327, Pittsburgh, PA 15237; telephone (412) 367-9111.

\section{Charles B. Duke Applauded for Contributions to Journal of Materials Research}

In a recent statement issued by MRS President Gordon E. Pike, the Materials Research Society recognized the contributions of Charles B. Duke, Xerox Webster Research Center, to the establishment and successful first year of publication of lournal of Materials Research. Duke, whosteps down from the position of Editor-in-Chief of JMR at the end of 1986, was instrumental in establishing the JMR editorial office, acquiring manuscripts, and publishing over 800 pages covering important interdisciplinary materials research during the Journal's inaugural year.

"Charlie Duke's contributions to the start-up of Jourmal of Materials Research are immeasurable," Pike stated. "The Journal was conceived in the middle of 1985 and under Charlie's direction published its first issue in early 1986. This was a phenomenal task that would not have been possible without Charlie at the helm. "The editorial office under Duke's direction established a board of Principal Editors, molded an editorial policy and peer-review procedure, and developed computer software for manuscript tracking and topical indexing of published papers. "Charlie's contributions have ensured Joumal of Materials Research as the premier fournal covering interdisciplinary materials research," Pike said. "The Materials Research Society, as well as the materials research community as a whole, is greatly indebted to Charlie for his insight and dedication. Thanks to Charlie's groundwork, IMR will continue to expand and thrive, serving as a keystone in modern materials research. 